\title{
Varying spatial patterns of trend and seasonality in Eurasian runoff time series
}

\author{
R. Rödel \\ Institute for Geography and Geology, Greifswald, Germany \\ Received: 23 January 2006 - Revised: 22 May 2006 - Accepted: 3 July 2006 - Published: 26 September 2006
}

\begin{abstract}
Atmospheric circulation indices can be used to explain the variability of runoff on a continental scale. Beside well-known regional anomalies of precipitation and runoff that correlate with phases of the North Atlantic Oscillation (NAO) there are also drifting fields of annual discharge anomalies. Following the trend of the NAO, these fields move along a longitudinal axis from western Europe to the Lena catchment in Siberia and back again. The same pattern is observable in the changing flow regimes. This paper describes the origin and causes of these anomaly fields and explains them as the results of important climate variations in the northern hemisphere.
\end{abstract}

\section{Introduction}

The stream discharge, which forms part of the water cycle, is one of the fastest mass and energy fluxes on earth. Discharge can be understood as a spatial integral consisting of climatic processes and direct anthropogenic impacts like river regulation. Discharge changes are expressions of changes in the components of that integral. Thus, global environmental changes can be detected as discharge effects. For this purpose, direct anthropogenic effects have to be singled out and subtracted in the analysis.

On a continental scale, changes of hydrological processes can be observed as trends or anomalies in discharge time series. The decadal and multi-decadal discharge variations in large-scale catchment areas are commonly studied using annual time series. The large-scale variability of annual global discharges is described by Peel et al. (2001). Dettinger and Diaz (2000) introduce a global data set of interannual discharge variability and correlate these data with atmospheric circulation indices like the El Niño/Southern Oscilla-

Correspondence to: R. Rödel

(roedel@uni-greifswald.de) tion (ENSO) index, the North Atlantic Oscillation (NAO) index and with climatic indices of the North Pacific region. The discharge amounts particularly of the South and North European river catchments are closely correlated with the phases of the NAO (Popova and Shmakin, 2003; Arnell, 1997).

However, on a continental scale, such correlations of climatic indices with annual discharges mostly are unsatisfactory. Only few time series clearly correlate with essential features of the climatic variability. Figure 1 shows that positive correlations of discharge data with the NAO are most frequent in northern Europe, while negative correlations clearly prevail in southern Europe. Arnell (1997) found the same basic pattern in the correlation of European winter discharges with the NAO index.

Nevertheless, the data from only one quarter $(24 \%)$ of Eurasia's gauging stations exhibit significant correlations between annual discharges (period 1950-1990) and the NAO index (Hurrel, 1995). This kind of correlation analysis presupposes an unchanging delimitation of the large-scale regions in which local discharges react uniformly to climatic fluctuations. If the region boundaries shift, then time-space processes provide a better explanation of the correlation between large-scale climate variability and river flows.

\subsection{Data}

This study is based on 3597 Eurasian discharge time series provided by GRDC (Global Runoff Data Centre) and adopted from NCAR (National Center for Atmospheric Research) ds552.1 and ds553.2 (Bodo, 2001) as well as from ArcticRiverNet (R-ArcticNET, 2005). Only years with complete monthly records were included in the analysis.

Nearly $70 \%$ of the time series span more than 30 years, but only $70 \%$ include the years until 1984, and only $40 \%$ until 1985. Detail studies were conducted using data from the climatological normal period (1960-1990). In addition, the

Published by Copernicus GmbH on behalf of the European Geosciences Union. 




Fig. 1. Significant correlations of Eurasian annual discharges time series with the NAO index 1950-1990 (NAO index after Hurrel, 1995).

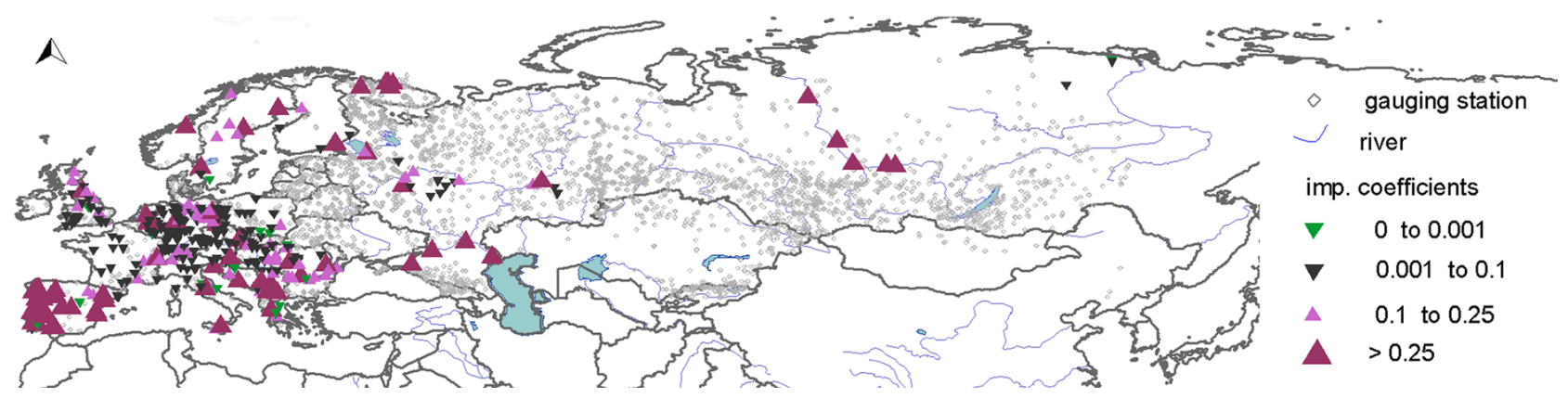

Fig. 2. Impoundment coefficients for Eurasia in 1990.

dfjm NAO index by Hurrel (1995) was employed to describe the phases of the NAO.

\section{Methods}

Successive changes in annual discharge amounts can be understood as trends in the discharge time series. If the discharges of individual catchments correlate with the climate variations generated by the NAO, this dependence should be detectable as deviations from the long-term average of the annual discharge. To determine the size of an anomaly, the long-term average annual discharge $\left(Q_{\text {average }}\right)$ was substracted from the individual annual discharge $\left(Q_{\text {year }}\right)$ and the result (the size of the anomaly) was standardised by $Q_{\text {average }}$. Because time series of different length, $Q_{\text {average }}$ was calculated based on all available values in a given time series instead of using only the values from a fixed standard period.

Spatial clusters of positive and negative discharge anomalies were detected by means of a hierarchical cluster analysis. The variables were the geographical latitude and longitude and the discharge anomaly. The standardised anomalies of each year were classified using Squared Euclidian Distance and Complete Linkage. Subsequently, the spatial centroids of each cluster were determined by computing the weighted average of latitude and longitude. Anomalies above 0.5 were weighted with the factor 0.6 , those between 0.25 and 0.5 were weighted with the factor 0.3 , and those between 0.1 and 0.25 were weighted with the factor 0.1 . Figures 3 and 4 show some centroid longitudes.

\subsection{Elimination of impoundment effects}

Many runoff time series are affected by impoundments. To assess the intensity of the impoundment impact on each of the 3647 gauging stations, their impoundment coefficients were computed. The impoundment coefficient is the ratio of the cumulated upstream reservoir capacity to the annual discharge. To assess the cumulated upstream reservoir capacity, reservoirs from the ICOLD database (ICOLD, 1998) in Europe and Russia were geo-referenced. The relevant upstream reservoirs and their cumulated capacity were determined using a digital elevation model and a digital river network (Rödel and Hoffmann, 2005).

Figure 2 shows the impoundment coefficients for Eurasia in 1990. Only 19 gauging stations had impoundment coefficients above 1 , and, therefore, the influence of impoundment on long-term annual discharges of Eurasia was neglected. Normally impoundment coefficients below 1 indicate that the water is redistributed only intra-annually (due to hydropower generation and flood protection). However, this applies more in humid than in arid regions.

For an analysis of the temporal variability of flow regimes, 354 gauging stations which were classified as daminfluenced (impoundment coefficients above 0.001 ) were removed from the data set. 
1970 NAO: -1.9
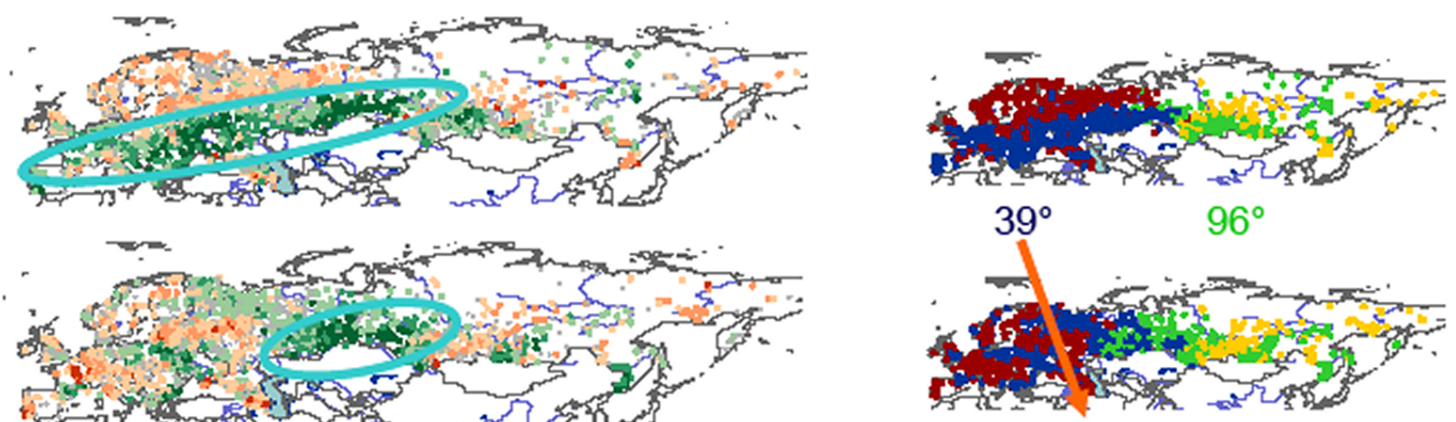

1971 NAO: -1.0


Fig. 3. Upward trend of the NAO - Left: A field of positive anomalies (wetter than average) in the annual discharges drifts from Europe to eastern Siberia. Right: Spatial clusters of positive anomalies (blue and green signatures) and longitudes of their centroids. Clusters of negative anomalies are shown in yellow and red. The longitudinal position of the clusters can be understood as a process response to the NAO. The arrow colour indicates the NAO trend.

\subsection{Balance point drift of discharge regimes}

Beside the temporal variability of annual discharges, Burn and Soulis (1992) focus on seasonal discharge variability as well as on the occurrence of extreme discharges and snowmelt induced floods. These floods react most obviously to climatic variability. In addition to the seasonal fluctuation in the hydrograph, the discharge regime is overlaid with the long-term variability of flow regimes themselves. Flow regimes change with the climate, and therefore it is possible to detect climate fluctuations in their time series. The stability of a flow regime can be defined as its appearance frequency (Krasovskaia, 1997; Krasovskaia et al., 1999).
For analysing regime changes, annual flow regimes were determined as an order of discharge coefficients, $q_{i}$ (Eq. 1):

$q_{i}=Q_{i} / Q_{\text {Year }} \quad$ with $\quad \sum_{i=1}^{n} q_{i}=1 \quad q_{i} \geq 0, \quad i=1, \ldots, 12$

where $Q_{\text {Year }}$ is the annual discharge and $Q_{i}$ is the monthly discharge. When the monthly discharges are standardised in this way, the transitions between the regimes of successive years appear abrupt. Unless the discharge sums of two successive years are virtually the same, the last month of year one and the first month of year two will have different coefficients, even if discharge is the same in both months. To minimise this distortion, the one-year period that the description of the runoff regimes was based on, was delimited in a way resembling the method used for hydrological years. The 


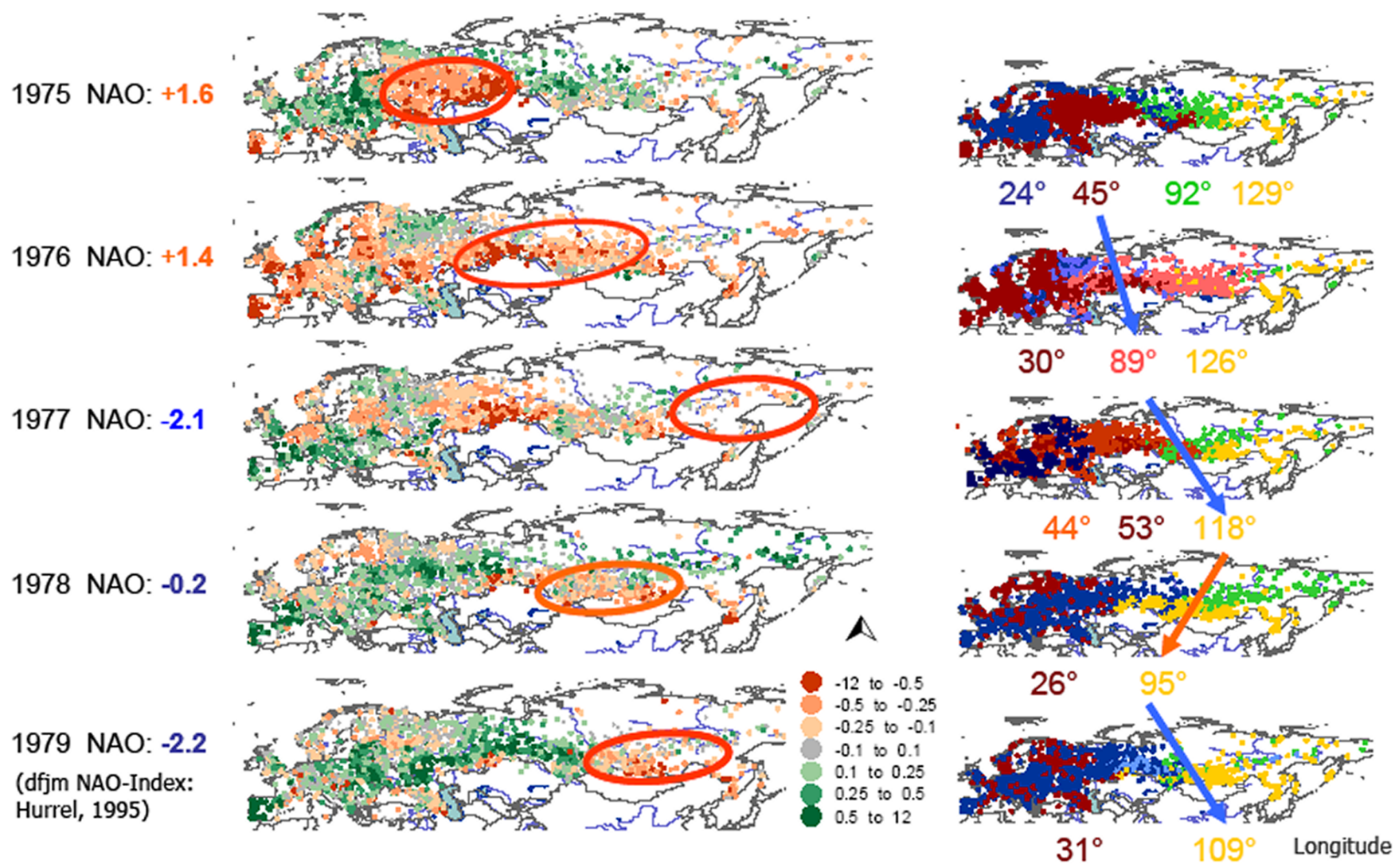

Fig. 4. Downward trend of the NAO - Left: A field of negative anomalies (dryer than average) of the annual discharges moves from western Siberia to eastern Siberia (NAO index: Hurrel, 1995). Right: Spatial clusters of negative anomalies (yellow and red signatures) and longitudes of their centroids. Clusters of positive anomalies are shown in blue and green. The longitudinal position of the clusters can be understood as a process response to the NAO. The arrow colour indicates the NAO trend.

beginning of the annual cycle was defined by that month $i$ which had the lowest square deviation from its average discharge value over the whole time series (Eq. 2):

$$
\sum\left(Q_{i}-\overline{Q_{i}}\right)^{2} \rightarrow \operatorname{Min!}
$$

Finally, changes in flow regimes were determined as an interannual shift of the balance point. Using the sum curves of the flow regimes $q_{i}$, the balance point is reached in that month $i$ for which

$\sum_{1}^{i} q_{i} \geq 0.5$

If the monthly discharge is constant (1/12 of the annual discharge), the balance point falls exactly in the sixth month of the cycle. To analyse the long-term variability of the balance point, the mode of balance points was calculated for each time series. Annual deviations from the mode were treated as positive or negative shifts of the balance point.

Negative balance point shifts co-occur with steep-shaped or early runoff maximum peaks. Negative shifts are typical for years with an above-average temperature and an earlierthan-usual snow melt in northern Eurasia. Positive balance point shifts are typical for flat-shaped runoff maximum peaks that occur later in the year than usual. In northern Eurasia, these shifts frequently occur in years in which the temperature is relatively low during the flood formation phase (the snow melt).

\section{Large-scale patterns at the trend level}

Time series from gauging stations in Eurasia were examined with regard to anomalies in the annual discharge and discharge seasonality, as well as their correlation with the NAO. The analysis revealed a pattern of regions in which local discharges react uniformly to climate fluctuations. But the region boundaries shift from year to year.

Figures 3 and 4 show the changes of the annual discharges during a downward and upward NAO trend, respectively. The uniform reaction regions lack the spatial stability demanded in Sect. 1. Beside the dipole structure, with higher 


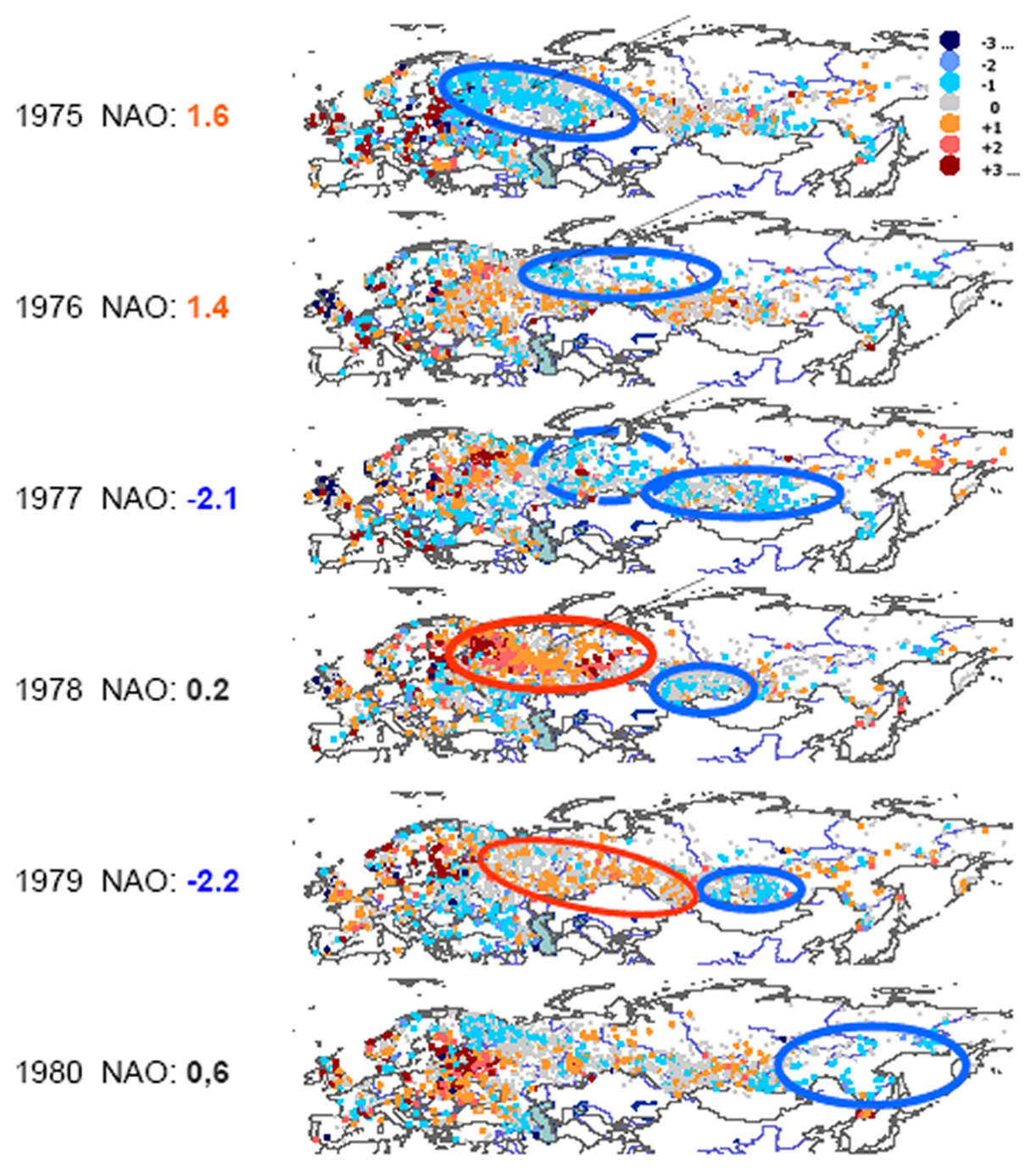

Fig. 5a. Downward trend of the NAO - a field of negative-shifted balance points drifts from north-western Russia to eastern Siberia. Strong runoff maxima which occur earlier than usual drift to eastern Siberia (NAO index: Hurrel, 1995). The small arrows indicate the location of gauging station SU91216 - see Fig. 5b.

runoffs in northern Europe and lower runoffs in southern Europe during a significantly positive NAO phase (Arnell, 1997), drifting fields of anomalies in the annual runoffs can be observed. These fields drift with the NAO trend along a longitudinal axis.

During an upward NAO trend (Fig. 4), these fields of reduced discharges move out of Siberia in a westward direction. At the same time, a field of increased discharges drifts eastward as far as the Lena catchment. The westwards moving fields of increased discharges co-occur with increased discharges in northern Europe during a positive NAO phase (Arnell, 1997; Timmermann and Latif, 1998). The periodical increase of discharges in eastern Siberia can be explained by the dependence between the NAO variability and the variability of the discharges.

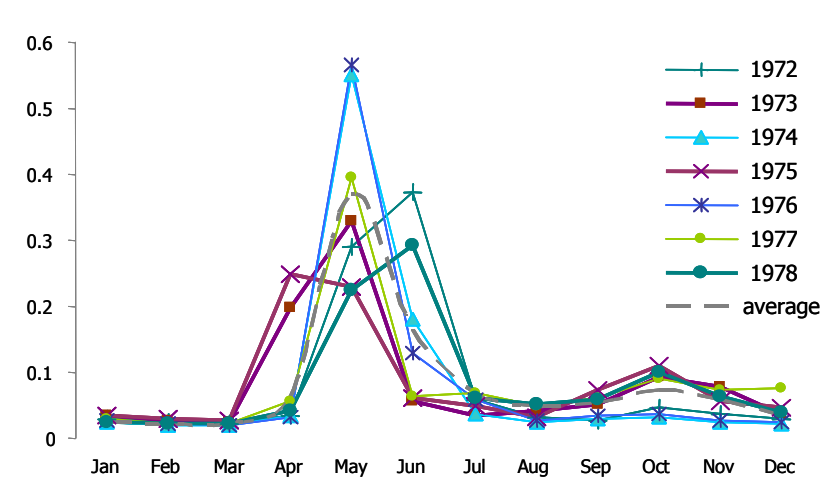

Fig. 5b. Standardised monthly flows (flow regime) for gauging station SU91216 Malaya Kuzhba, Vychegda (data from Bodo, 2001). 
1981 NAO: 2.0

1982 NAO: 0.8

1983 NAO: 3.4
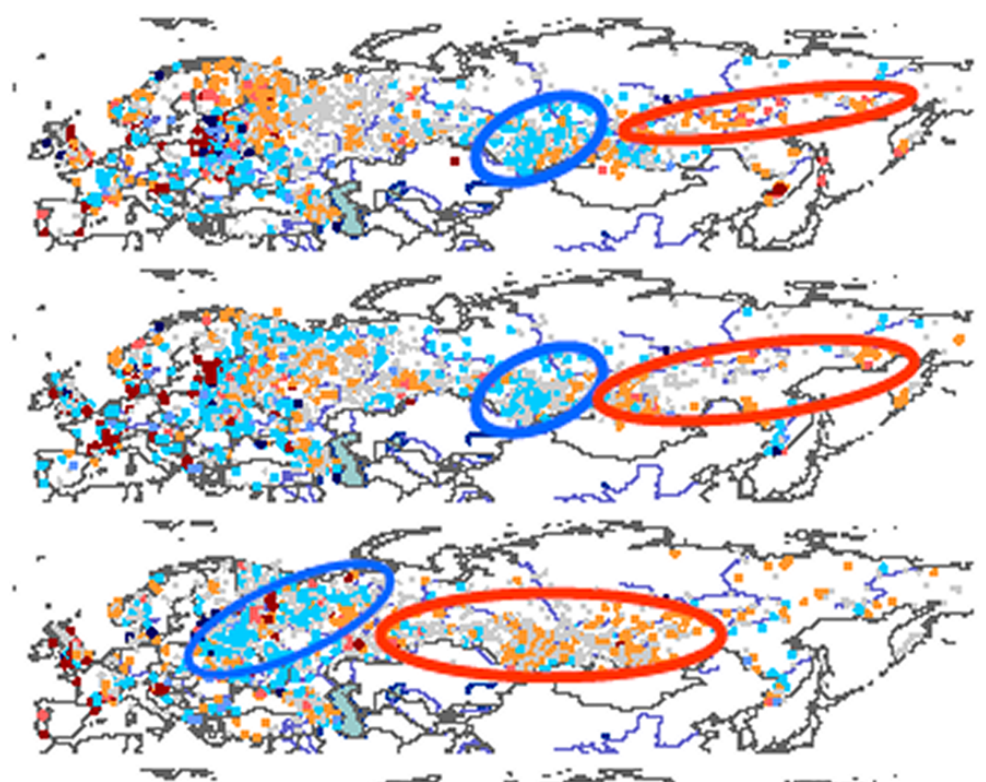

1984 NAO: -0.6

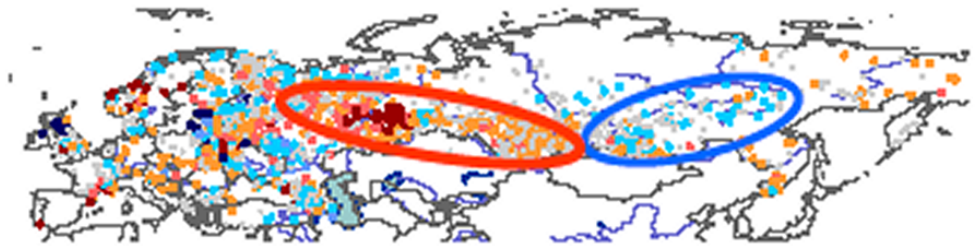

1985 NAO: 0.5

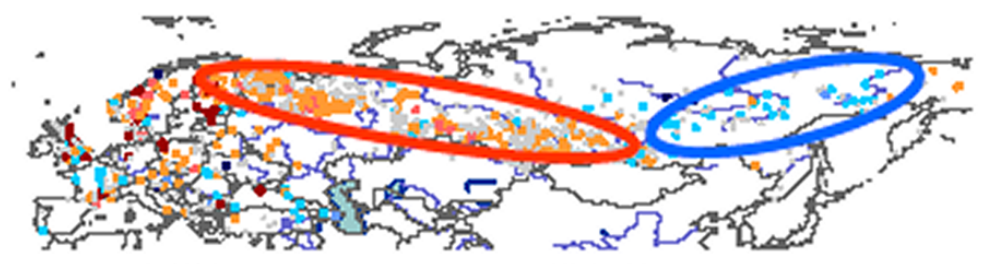

1986 NAO: -0.8



Fig. 6. Upward trend of NAO. A field of positive-shifted balance points drifts westwards and leaves eastern Siberia. 1983-1986: Transition to a different NAO phase. north-western Eurasia is characterised by the field of positive shifted balance points. A field of negative-shifted balance points replaces the fields of positive shifted balance points (observable until 1983) over eastern Siberia (NAO index: Hurrel, 1995).

During a downward NAO trend, fields of reduced discharges (represented as negative deviations from the longterm average of the annual discharges) drift eastwards from western Russia as far as the Lena catchment in eastern Siberia (Fig. 4).

Mysak (1999) stated that fluctuations of annual discharges in large-scale catchments are strongly correlated with decadal climate fluctuations. He suggests that the longterm variation in the discharge volumes of the Mackenzie catchment area is the major reason for the formation of great ice and salt anomalies (GISA) in the North Atlantic. These anomalies influence the intensity of oceanic circulation with a delay of three to four years and control the climate of the northern hemisphere through the NAO and the Arctic Oscillation. Reduced salinity causes a weaker thermohaline circulation in the North Atlantic (negative NAO index) (Timmermann and Latif, 1998). Although Mysak (1999) focuses on increased discharges in the Mackenzie catchment area, he also points out that increased discharges from Siberian streams contribute to the formation of ice covers in the Arctic Ocean. 


\section{Large-scale spatial patterns of seasonal discharge variability}

Figure 5a shows that the shifts in the balance points of flow regimes form a spatial pattern of drifting fields. This is the same basic phenomenon as that observed in the deviations of the annual discharges from their long-term average (Sect. 2). Fields of increased discharges drifting to Siberia are followed by fields of negative-shifted balance points. The balance point fields seem to drift in correlation with the phases of the NAO.

During a downward trend of the NAO, a field of negativeshifted balance points drifts eastwards as far as the Lena catchment (Fig. 5a). This field is caused by a positive NAO phase lasting from 1972 until 1975. Figure 5b shows the flow regimes connected with negative shifts of the balance points. In 1973 and 1975 - during mild winters - the runoff maxima occur earlier than usual. The flow regimes in 1974 and 1976 are characterised by steep-shaped runoff maximum peaks. When the pattern of a positive NAO phase (a dipole pattern of annual discharges in Europe) dissolves, the field of negative-shifted balance points drifts eastwards. During an extreme negative phase of the NAO, a field of positive-shifted balance points can be observed in north-western Russia. This field is characterised by a flat-shaped runoff maximum peak occurring later than usual. Figure $5 \mathrm{~b}$ shows such a typical flow regime (in the year 1978). The causes of this effect are the relatively low temperatures during the flood formation phase (the snow melt).

During an upward trend of the NAO (Fig. 6), the balance point fields move in the opposite direction. Fields of negative shifted balance points drift back westwards from eastern Siberia. At the same time, the annual discharges in northern Europe are higher than average.

\section{Conclusions}

Assuming that the NAO is the driving process for drifting fields of discharge anomalies and that discharge represents the response of river flow to the NAO, the centroid longitudes of discharge anomaly clusters were identified (cf. Figs. 3 and 4). For example, in the analysis of a time series segment coinciding with an upward trend of the NAO, the easternmost cluster of positive discharge anomalies is singled out at each timestep (Fig. 7). This leads to an understanding of cluster shifting as an autoregressive process. Thus, the location of a cluster can be determined from its location at $t-1$ and the drifting direction. The drifting direction itself can be obtained from the NAO index.

The results presented here lead to the hypothesis that discharge variability reflects large-scale hemispheric climate variability better than previously assumed (cf. Arnell, 1997; Dettinger and Diaz, 2000; Popova and Shmakin, 2003). Anomalies in annual discharges and shifts of the balance

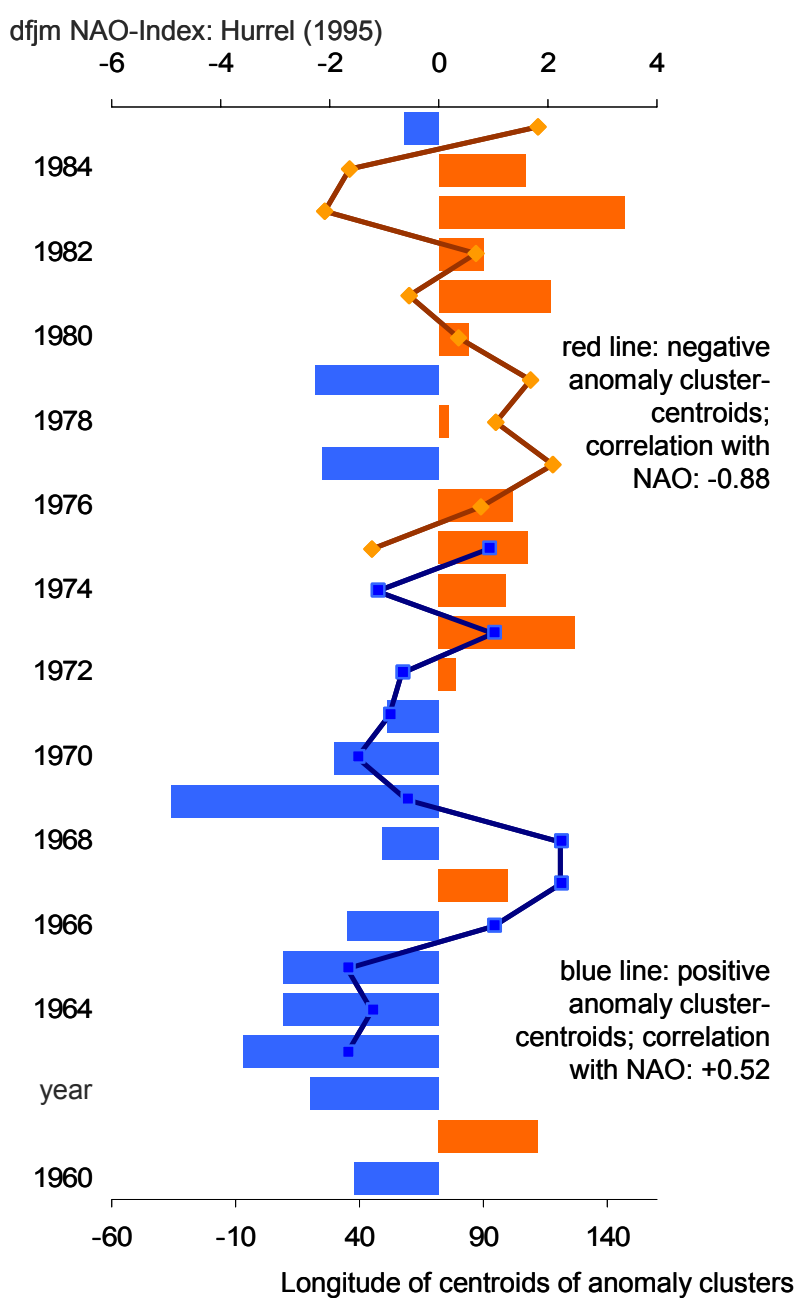

Fig. 7. Longitudinal drifting of large-scale patterns of discharge anomalies in Eurasia (lines) and the NAO index (bars).

points of annual flow regimes point to those regions which are important for processes of climate variability in the northern hemisphere. The NAO provides a basis for explaining large-scale anomalies of the annual discharges and of the river flow regimes in Eurasia.

Acknowledgements. The author thanks the GRDC - Global Runoff Data Centre, Koblenz, Germany, for providing the data from several gauging stations, P. Pratap Thapa for manuscript revision and the two referees for improving this paper. Also thanks to the conveners of the workshop for the excellent organisation.

Edited by: R. Barthel, J. Götzinger, G. Hartmann, J. Jagelke, V. Rojanschi, and J. Wolf

Reviewed by: anonymous referees 


\section{References}

Arnell, N. W.: Spatial and temporal variability in European river flows and the North Atlantic oscillation, in: FRIEND '97 - Regional Hydrology, edited by: Gustard, A. and S. Blazkova, IAHS Publ. No. 264, Wallingford, 77-85, 1997.

Bodo, B. A.: Monthly Discharge Data for World Rivers V1.3, NCAR, http://dss.ucar.edu/, files ds552.0, ds553.2 and the US data, 2001, date of access: 10.11.2005.

Burn, D. H. and Soulis, E. D.: The Use of Hydrologic Variables in Detecting Climate Change: Possibilities for Single Station and Regional Analysis, in: Using Hydrometric Data to Detect and Monitor Climatic Change, Proceedings of NHRI Symposium No. 8, April 1991, Saskatoon, 1992.

Dettinger, M. D. and Diaz, H. F.: Global Characteristics of Stream Flow Seasonality and Variability, J. Hydrometeorol., 1, 8, 289310, 2000.

GRDC - data provided by Global Runoff Data Centre (http://grdc. bafg.de/), Koblenz, Germany.

Hurrel, J. W.: Decadal Trends in the North Atlantic Oscillation Regional Temperatures and Precipitation, Science, 269, 676-679, actual data see: http://www.cgd.ucar.edu/cas/jhurrell/ indices.html (date of access: 10.11.2005), 1995.

Krasovskaia, I.: Entropy-based grouping of river flow regimes, J. Hydrol., 202, 173-191, 1997.
Krasovskaia, I., Gottschalk, L., and Kundzewicz, Z. W.: Dimensionality of Scandinavian river flow regimes, Hydrol. Sci. J., 44(5), 705-723, 1999.

Mysak, L. A.: Interdecadal Variability of northern High Latitudes, in: Beyond El Niño, Decadal and Interdecadal Climate Variability, edited by: Navarra, A., Springer, Berlin, Heidelberg, 1-23, 1999.

Peel, M. C., Mc Mahon, T. A., Finlayson, B., and Watson, F. G. R.: Identification and explanation of continental differences in the variability of annual runoff, J. Hydrol., 250, 224-240, 2001.

Popova, V. V. and Shmakin, A. B.: Influence of the North Atlantic Oscillation on multiyear hydrological and thermal regime of northern Eurasia. I. Statistical analysis of observational data, Russ. Meteorol. Hydrol., 5, 47-56, 2003.

R-ArcticNET (v3.0): http://www.R-ArcticNET.sr.unh.edu, date of access: 10.11.2005.

Rödel, R. and Hoffmann, T.: Quantifying the efficiency of river regulation, Adv. Geosci., 5, 75-82, 2005, http://www.adv-geosci.net/5/75/2005/.

Timmermann, A. and Latif, M.: Thermohaline Circulation - a coupled node of the NAO, J. Clim., 11, 1906-1931, 1998.

Zhuravin, S. A.: Change of hydrological regimes over the central part of European Russia resulting from climate variations, in: FRIEND 2002 - Regional Hydrology, edited by: van Lanen, H. A. J. and S. Demuth, IAHS Publ. No. 274, Wallingford, 441-447, 2002. 